\title{
Erratum to: In the Eye of the Beholder: Recovery and Personal Narrative
}

\author{
W. Patrick Sullivan ${ }^{1} \cdot$ Vincent R. Starnino $^{1} \cdot$ Catherine G. Raster $^{2}$
}

Published online: 21 September 2017

(C) Springer (India) Private Ltd. 2017

\section{Erratum to: J. Psychosoc. Rehabil. Ment. Health DOI 10.1007/s40737-017-0097-6}

The given name and family name of the first author Dr. W. Patrick Sullivan was swapped in the original publication. The correct name should read as W. Patrick Sullivan.

The online version of the original article can be found under doi:10.1007/s40737-017-0097-6.

Vincent R. Starnino

vstarnin@iupui.edu

W. Patrick Sullivan

wpsulliv@iupui.edu

1 School of Social Work (IUPUI), Indiana University, $902 \mathrm{~W}$.

New York Street, Indianapolis, IN 46202, USA

2 School of Social Work, Boston College, McGuinn Hall, Chestnut Hill, MA 02467, USA 